\title{
Cadenas Globales de Valor y Desarrollo: Perspectivas Críticas desde el Sur Global
}

\author{
Víctor Ramiro Fernández ${ }^{1}$ \\ Manuel Facundo Trevignani ${ }^{2}$ \\ ${ }^{1}$ Universidad Nacional del Litoral (UNL). Santa Fé, Argentina. E-mail: \\ rfernand@fcjs.unl.edu.ar \\ ${ }^{2}$ Universidad Nacional del Litoral (UNL). Santa Fé, Argentina. E-mail: \\ mtrevignani@hotmail.com
}

\section{INTRODUCCIÓN}

T a discusión sobre el enfoque de cadenas globales de valor ( $\mathrm{GVC}^{1}$ ) $\amalg$ se ha transformado en la última década en una herramienta de gran relevancia no solo para el análisis de las redes económicas globales en base a las cuales funciona crecientemente el capitalismo, sino también para la formulación de las políticas de desarrollo. Con ello, esta perspectiva ha tenido una creciente, aunque no siempre homogénea, asimilación institucional. De hecho, ha pasado a formar parte de las categorías que integran el repertorio de los organismos supranacionales, que comprenden tanto aquellos más ligados al diagnóstico y el asesoramiento (los vinculados a Naciones Unidas) como, más recientemente, aquellos que han operado como financiadores de las estrategias que, en su momento, fueron fuertemente dominadas por el Consenso de Washington (Fernández, 2015).

No obstante su importancia y contribuciones, al momento de ser evaluado como herramienta de desarrollo en el Sur Global ${ }^{2}$, ese proceso de institucionalización supranacional exhibe un conjunto de debilidades que tienen como punto de partida la perspectiva reducida a lo empresarial e interempresarial asumida por el enfoque dominante que lo alimenta (Gibbon y Ponte, 2005; Bair, 2008). Esa orientación reductivista, por su parte, ha sido edificada a partir de una serie de distanciamientos/silenciamientos, al tiempo que de continuidades teórico-

DADOS - Revista de Ciências Sociais, Rio de Janeiro, vol. 58, n-2, 2015, pp. 499 a 536.

http://dx.doi.org/10.1590/00115258201551 
empíricas respecto de la teoría del sistema-mundo (TSM) que le dio origen. A partir de ellas, resulta una marcada restricción del enfoque como herramienta de análisis de las transformaciones actuales, así como también para el diagnóstico y alternativas para los países en desarrollo y las macrorregiones a las que pertenecen. El presente trabajo pretende considerar esas limitaciones, bien como tratar de orientar su superación.

El alejamiento más visible y relevante del enfoque de GVC, producto del mencionado centramiento en empresas y redes interempresariales, se da respecto del funcionamiento de las cadenas en el marco general del sistema capitalista y su forma de reproducción contradictoria y jerárquica, aspectos que tuvieron un papel central en el propio origen del concepto bajo la perspectiva de la teoría del sistema-mundo (Hopkins y Wallerstein, 1986). La superación de ese distanciamiento y su más holística reinserción en la lógica y tendencias desigualadoras de ese sistema emerge como requerimiento para permitir que las GVC pasen a ser consideradas no como "lonjas" sectoriales (sectoral slices) tal como sugerido por Bernstein y Campling (2006), sino como partes de un todo. Ello hace posible reemplazar su papel, como instrumento para estimular la articulación de actores de los países periféricos a esa estructura jerárquica, por otro centrado en la detección de los efectos estructuralmente desigualadores, generados por el control diferencial agregado de las actividades centrales de las cadenas a escala global por parte de empresas mayoritariamente localizadas en los centros del sistema-mundo.

Sin embargo, las restricciones del enfoque dominante de GVC no demandan sólo recuperar esta dimensión holística, contradictoria y jerárquica de la TSM, sino también romper con ciertos aspectos compartidos con este enfoque, vinculados al desplazamiento de la relevancia de las trayectorias nacionales y la relativización del papel de los Estados-nación como unidades de análisis para explicar las diferentes performances en la dinámica global del capitalismo.

En el presente artículo, sostenemos que la recuperación analítica de esas trayectorias y de los Estados-nación bajo el reconocimiento de la perspectiva holística, contradictoria y jerárquica del capitalismo de la TSM, conlleva la posibilidad y necesidad de considerar los patrones diferenciados de acumulación e inserción global. Éstos, a su vez, resultan no sólo de las particulares relaciones de las empresas en una red 
trasnacional, sino también del complejo de elementos institucionales y económicos (nacionalmente situados y macrorregionalmente afectados) que dan lugar a respuestas específicas, no convergentes, que tienen los países y macrorregiones del Sur Global donde esas empresas se emplazan.

Asimismo, sugeriumos que la reformulación del enfoque de GVC para dar cuenta de lo indicado otorga un marco estructural y dinámico para comprender las potencialidades y limitaciones que enfrentan los actores del Sur Global en la multiplicidad de encadenamientos que lo atraviesan. Permite, además, identificar elementos esenciales para las estrategias de desarrollo orientadas a superar los posicionamientos periféricos y subordinados en la jerarquía global de los espacios nacionales y macrorregionales a los que pertenecen.

El texto se estructura en tres partes, además de esta introducción. Se analiza, en primer lugar, la evolución del concepto de cadenas globales de valor, observando el paso desde su concepción como perspectiva sistémica y holística a una visión orientada a franjas sectoriales. En la segunda sección, conjuntamente con el sustento empírico correspondiente, se consideran las limitaciones vinculadas a dos horizontes: por un lado, el distanciamiento respecto del todo contradictorio y jerárquico instalado por la TSM; y, por otro, las restricciones derivadas de la plataforma teórica común respecto de esa teoría, fundadas en el anulamiento de la dimensión nacional y los Estado-nación como unidades estratégicas de análisis. En tal contexto, se afirma, finalmente, la importancia de esas unidades para explicitar tanto el nuevo dinamismo del Sur Global como las rutas diferenciadoras que tienen lugar al interior del mismo entre el este asiático y el resto de las grandes áreas que lo componen.

Con base en los resultados encontrados, el trabajo concluye afirmando el desafío de reconducir el enfoque de GVC hacia las pautas mencionadas. Es decir, hacia un marco analítico más holístico que reinserte el enfoque en la totalidad contradictoria del capitalismo con sus formas de jerarquización y subordinación, pero también con sus actuales transformaciones funcionales y espaciales de gran escala, que incluyen el reciente ascenso del Sur Global. En este escenario, reiteramos la necesidad de evaluar las estrategias hacia y desde el enfoque de GVC a partir del reconocimiento de las fortalezas y debilidades que deparan las particulares trayectorias nacionales para los actores involucrados, con sus 
específicos patrones de acumulación y configuración estatal. Proponemos, por lo tanto, una recuperación de los Estados nacionales y de la escala nacional como unidad de análisis estratégica que convive y se retroalimenta comprensivamente con el marco de esa totalidad jerárquica y contradictoria de la TSM.

\section{EVOLUCIÓN DEL ENFOQUE DE LAS CADENAS GLOBALES DE VALOR}

\section{Las Cadenas de Mercancías en el Marco de la Teoría del Sistema-Mundo}

El concepto actualmente utilizado como cadenas globales de valor (GVC) tiene su origen en la obra de Hopkins y Wallerstein (1977), quienes elaboran la noción de cadenas de mercancías (commodity chains) en su desarrollo de la teoría del sistema-mundo (Wallerstein, 1974; 1976) ${ }^{3}$. Los autores sostienen que la economía-mundo capitalista actual se encuentra conformada por una única división internacional del trabajo, pasible de descomponerse en una serie de cadenas mercantiles que, a partir de la articulación de diversos procesos productivos, traspasan las fronteras interestatales.

En su investigación acerca del funcionamiento de la economía-mundo capitalista y con el objetivo de rastrear las relaciones de producción en el tiempo y en el espacio, los autores definieron las cadenas de mercancías como las redes de procesos de trabajo y producción que dan lugar a una mercancía terminada. Es decir, la construcción del concepto parte desde el producto final, retrocediendo hacia atrás en el proceso de producción hasta la obtención de la materia prima. De este modo, se podrá indagar en las fuentes de valor de ese producto terminado e identificar los "nodos" de cada una de las cadenas. Esta perspectiva considera que la economía mundial está estructurada jerárquicamente en tres eslabones - centro-semiperiferia-periferia ${ }^{4}$ - que no vinculan economías nacionales entre sí, sino actividades económicas que son estructuradas por estas cadenas (Arrighi y Drangel, 1986). Como consecuencia, el valor agregado por cada una de estas actividades y las formas de apropiación del mismo permiten identificar: a) actividades centrales: aquellas que absorben la mayor parte de los beneficios producidos dentro de la cadena; b) actividades periféricas: las que sólo se apropian de una porción marginal del beneficio. La distribución de actividades y valores fundamenta la desigual apropiación de beneficios del intercambio internacional existente entre las mismas (Arrighi y 
Drangel, 1986; Wallerstein, 1974), explicando la existencia de una estructura jerárquica y desigual.

En virtud de lo mencionado, este marco da cuenta de un nuevo paradigma al tratar con cuestiones ligadas a la distribución de la riqueza entre las naciones, ya que los procesos de innovación y producción dentro de los diferentes nodos que conforman una cadena de mercancía juegan un papel transcendental a la hora de la distribución del capital global.

El análisis de las cadenas dentro de ese marco teórico contribuye a la comprensión del sistema-mundo moderno como una totalidad contradictoria, dado que dicho concepto inicialmente fue utilizado como un mecanismo para estudiar la historia cíclica, contradictoria y desigual del capitalismo desde sus inicios en el siglo XVI - la larga duración en términos de Braudel -, más que como una herramienta para analizar las transformaciones recientes de la economía global (Bair, 2005). No obstante, aunque el concepto actual de cadenas globales de valor (Sturgeon, 2008) tenga su origen en la TSM, no sólo ve mutar su terminología, sino que gira hacia una perspectiva centrada en empresas o aglomeraciones y pierde de vista la dimensión holística de su fuente de origen.

\section{Desde las Cadenas Globales de Mercancía a las Cadenas Globales de Valor}

En la década de 1990, con el auge de las ideas neoliberales, una nueva concepción del enfoque nació de la mano de los estudios iniciados por Gereffi $(1994 ; 2001)$ para dar cuenta de esta nueva reconfiguración a nivel mundial que tuvo lugar en los últimos dos decenios. En este sentido, Gereffi realiza cambios significativos del objeto de estudio respecto a la TSM, transformándolo en una visión centrada en empresas, en las cadenas globales de mercancías o en redes de empresas, como en la más reciente perspectiva de GVC. La inclusión del término "global" en el concepto originario de "cadenas de mercancías" no tiene que ver con un mayor alcance geográfico de la cadena, sino que refiere a la diferenciación que Gereffi realiza, siguiendo a Dicken (1998), entre internacionalización y globalización ${ }^{5}$. Por otro lado, el cambio del término "mercancía" por "valor" fue implementado a fin de disociar las mercancías de los productos primarios con el objeto de incorporar otro tipo de productos, como el sector servicios (Gibbon y Ponte, 2005:77). 
En los primeros trabajos donde se desarrolla la noción de cadenas globales de mercancías (Gereffi et al. 1994; Gereffi, 1994), se distinguen dos tipos ideales de redes económicas internacionales que caracterizan la globalización: las cadenas dirigidas por el productor y aquellas dirigidas por el comprador. Las primeras reflejan las industrias de capital y tecnología intensiva - como las automotrices, aeronáutica, computación, etc. - donde las grandes empresas trasnacionales adquieren un papel central en la coordinación de estas redes (Gereffi, 2001). Ya las segundas, se refieren a industrias de capital comercial - como la indumentaria, calzado y juguetes -, donde las competencias centrales son el diseño y la comercialización, y cuya producción generalmente se encuentra situada en los países periféricos. Las cadenas de mercancías se encuentran distribuidas entre numerosas empresas independientes, en las cuales las empresas líderes son las que llevan adelante el proceso de coordinación y las que controlan las actividades centrales dentro de la misma. En este sentido, para poder triunfar en la actual economía mundial "los países y empresas necesitan ubicarse estratégicamente en estas redes globales y desarrollar estrategias para tener acceso a las empresas líderes y mejorar así sus posiciones" (Gereffi, 2001:13) ${ }^{6}$.

A comienzos del presente siglo, este enfoque se complementó con el de GVC en un intento de aglutinar otros estudios acerca de las cadenas globales y del funcionamiento de las industrias en la globalización económica (Bair, 2005). En este marco, Gary Gereffi, junto a investigadores vinculados a J. Humphrey, R. Kaplinsky T. Sturgeon comenzaron a desarrollar estudios de casos en países periféricos y a elaborar trabajos conjuntos, articulados luego a partir de la creación de la red de investigación interdisciplinaria denominada Global Value Chains Initiati$v e^{7}$, encargada de condensar la producción académica relacionada con la temática. Uno de los aspectos centrales bajo los cuales evolucionaron los estudios difundidos por la red estuvo vinculado a la dimensión de la gobernanza en las cadenas globales. Gereffi et al. (2005) identificaron cinco tipos de estructuras que reflejan las relaciones entre sus miembros - jerárquica, cautiva, relacional, modular y mercantil -, según el grado de coordinación y asimetría de poder existente, así como también los costos de transacción asociados. A su vez, los autores concluyen su teoría sosteniendo que las estructuras de las cadenas de valor dependen críticamente de tres variables independientes, a saber: la complejidad de las transacciones, la capacidad de codificar las transacciones y de las capacidades de suministro. 
De esta manera, el análisis de GVC provee una herramienta conceptual y metodológica para observar la economía global a partir de su esquema "top down-bottom up" (Gereffi, 2013), donde se agrupan los dos conceptos clave en el enfoque: la gobernanza y el ascenso o mejora (upgrading). El primer término del binomio se centra en la firma líder de una determinada cadena y en las redes interfirmas mediante la utilización de las tipologías de gobernanza industrial descriptas anteriormente, donde queda expuesto que no todas las firmas de la cadena son similares en cuanto al poder que ostentan. Por otra parte, el ascenso se refiere al progreso en la posición de la cadena por parte de una firma a partir de un mayor control del valor agregado en una actividad. En virtud de ello, este último concepto parece haberse convertido en el objetivo primordial dentro de este enfoque y en el cual sus académicos basan sus investigaciones (Gereffi, 2013).

El debate sobre las cadenas globales de valor ha encontrado otros enfoques muy cercanos, aunque parcialmente críticos, como el de redes globales de producción liderado por Peter Dicken y la Escuela de Manchester. Dicken et al. (2001) reconocen su base teórica en la literatura de GVC, aunque observan cierta linealidad en la noción de cadenas, debido a la no consideración de "los flujos de materiales, los productos semiterminados, el diseño, la producción, y los servicios de marketing y financieros están organizados vertical, horizontal y diagonalmente en configuraciones complejas y dinámicas" (Dicken et al., 2001:99). En virtud de ello, introducen el concepto de redes en reemplazo de cadenas con el fin de lograr una noción más inclusiva.

No obstante estas diferencias críticas, no ha emergido un cuerpo teórico alternativo ya que todos estos estudios comparten finalmente la orientación de su investigación hacia el análisis de las formas y el papel de las redes trasnacionales y multilocalizadas de empresas, razón principal por la cual la discusión sobre las cadenas globales de valor logró finalmente consolidarse y expandirse académica e institucionalmente. De hecho, el enfoque de las GVC se ha convertido en una herramienta importante para el análisis de las redes económicas globales sobre las que se estructura el capitalismo moderno y, a su vez, como instrumento para la generación de políticas de desarrollo.

Organismos supranacionales, ya sean aquellos vinculados a Naciones Unidas - como la OIT, PNUD, ONUDI, CEPAL -, las instituciones financieras - BID, BM y FMI -, y la propia OCDE pasaron a utilizar este 
enfoque como referencia (Werner et al., 2014). No obstante, el proceso no representa solo una relación organismos-Estados, sino que ha calado en un cuerpo socialmente más complejo que incluye diversos actores y organizaciones, como las organizaciones no-gubernamentales (ONG). Desde los organismos citados se promueve las ONG como actores centrales en sus programas, que actúan como la tercera parte representante de la sociedad civil en la creación del valor (realizado por las empresas) y la gobernanza (efectuada por los Estados), y su principal función es actuar de nexo entre lo local y lo global, muchas veces soslayando la escala nacional.

En esa línea, Pietrobelli y Staritz (2013:33) sostienen en su informe para el BID que "el enfoque de cadenas de valor también hace hincapié en la importancia del upgrading de actores no empresariales, como los Estados y organizaciones regionales e internacionales, asociaciones empresariales, sindicatos, ONG, proveedores de servicios, organismos de investigación y formación, e instituciones reguladoras". Al capitalizar la interacción creciente de ese complejo de actores, bajo el impulso central de los organismos supranacionales, el concepto de GVC parece haber operado sobre el fuerte desprestigio que sufrieron los dispositivos conceptuales ligados al neoliberalismo - como el Consenso de Washington -, posicionándose como una nueva herramienta de interpretación y acción vinculada al desarrollo en la agenda internacional a partir de mediados de la década pasada (Fernández, 2015).

No obstante compartir la misma matriz académica que la perspectiva de las cadenas globales de mercancías, el enfoque de GVC se ha posicionado como el concepto y la perspectiva de mayor reconocimiento a partir de la adición de otras dimensiones - como lo señalado con relación a la gobernanza en las cadenas. Al lograr este reconocimiento, ha sido diluido el abordaje holístico e integral de todo el sistema capitalista, así como la pervivencia de su estructura jerárquica y desigualadora, cuestiones impulsadas originalmente por Wallerstein y Hopkins. Por el contrario, las empresas particulares y las cambiantes redes y funciones que ellas configuran se convirtieron en foco central de análisis. De este modo, ni el concepto de cadenas globales de valor ni tampoco el de caneas globales de mercancías representan una mera alteración terminológica respecto al debate conceptual fundante, sino una variación esencial en su significado, en tanto se alejan de la comprensión holística de la estructura capitalista, la conformación de centros y periferias y 
la dinámica asimétrica en su historia, para pasar al papel de las firmas dentro del actual proceso de globalización (Bair, 2008).

\section{LAS LIMITACIONES DEL ENFOQUE DE LAS CADENAS GLOBALES DE VALOR Y SU RELACIÓN CON LA TEORÍA DEL SISTEMA-MUNDO}

Aunque la Escuela de Manchester y su enfoque sobre redes globales de producción han arrojado fuertes críticas sobre el debate de las cadenas globales de valor, buscando trascender los límites de los estudios sobre globalización centrados en los Estados como unidad principal de análisis (Dicken et al., 2001; Henderson et al., 2002; Coe y Hess, 2005; Hess y Yeung, 2006), estas limitaciones aún requieren una comprensión y articulación más profunda. Todavía es necesario determinar de manera más precisa sus consecuencias y superar un peligroso eclecticismo que perdura en gran parte de la literatura. Para ello, sugerimos que es necesario retomar el análisis de su constitución y lógica en forma comparada con la TSM, a la que, paradojalmente, el enfoque de las redes globales de producción ha relativizado. Ello demanda retomar un análisis sobre su constitución y lógica, marcando los puntos de proximidad y alejamiento con la teoría del sistema-mundo.

\section{Comparación y Diferenciación de las Perspectivas}

En el análisis de la evolución del concepto de cadenas de valor previamente realizado, se resalta que el mismo ha ido evolucionando desde una perspectiva más ligada a la comprensión del capitalismo como un todo, que se despliega históricamente, a otra en la que domina una perspectiva básicamente empresarial y sectorial, que analiza las redes de entidades que forman la especificidad de los procesos de globalización. En términos reales, ese cambio no representa solamente un "acotamiento en el objeto", o un "cambio en el corte temporal del análisis" (Bair, 2008), sino una forma epistemológicamente diferente de analizar la globalización (Robinson, 2011) que no resulta inocua con relación a la comprensión de procesos y a la elaboración de estrategias.

Dentro de esta discusión, la teoría del sistema mundo, aunque pueda incluso no considerarse una teoría en sentido estricto (Wallerstein, 2004a), representa un análisis destinado a comprender el capitalismo como un "todo de larga duración", que se reproduce en forma contradictoria y jerárquica, perpetuando distintas formas de desigualdad bajo la continuidad centro, periferia y semi-periferia. A su vez, el enfo- 
que de las cadenas globales de valor representa un intento de examinar los actuales procesos de globalización como un hecho novedoso, a partir del examen de la forma en que funcionan determinadas redes sectoriales de empresas con las actividades que las conectan a escala global, configurando formas de gobernanza específicas que explican el posicionamiento y las posibilidades de incorporarse a las mismas por parte de empresas y sectores esencialmente de los países periféricos (Gereffi et al., 2005).

En el marco de esta comparación general, emergen cuatro elementos diferenciadores entre las dos propuestas analíticas, vinculados a la temporalidad, a la unidad central de análisis, a la dinámica que imponen los actores y a la conceptualización del poder presente en una y otra perspectiva.

a) Temporalidad en el proceso de análisis: larga duración vs. especificidad del proceso de globalización

El primer aspecto diferenciador entre la TSM y el enfoque de GVC es que, en la primera, el análisis de las cadenas de mercancías se inserta dentro de un proceso temporal de larga duración, sobre el cual se edifica y dinamiza el capitalismo a partir de procesos cíclicos y sistémicos de hegemonías, crisis de determinadas unidades hegemónicas y relevo de otras. Inspirado en la contribución seminal de Braudel, la mirada de longue dureé inserta el análisis de las cadenas globales de mercancías en y para la comprensión de la lógica histórica, cíclica y contradictoria del capitalismo desde el siglo XVI. En otras palabras, las cadenas de mercancías se insertan dentro de un: “...proceso histórico en el que todo cambio es lento, con una constante repetición de ciclos recurrentes" (Robinson, 2011:4). Analizar las cadenas dentro de tal proceso histórico significa, como indica Bair (2005), que: “...las cadenas de mercancías no son un fenómeno reciente, que data de la década de 1970 o incluso 1945, sino que han sido una parte integral del funcionamiento de la economía-mundo capitalista desde el comienzo de su existencia en el largo siglo XVI (Wallerstein, 2000:2)". Por su parte, al igual que las cadenas de mercancías, el proceso de globalización, lejos de ser comprendido como algo distintivo que requiere un particular herramental de análisis, se considera parte de esa larga duración del sistema capitalista y se expresa "como una mera intensificación cuantitativa de conexiones e intercambios sistemáticos que datan desde el año 1500 aproximadamente" (Robinson, 2011:13). 
En cambio, el enfoque de GVC analiza las cadenas para considerar, como muchos otros enfoques, la especificidad de la globalización, erigida en el marco de la reestructuración con posterioridad a la crisis de los años 70. En tal sentido, viene a formar un novedoso instrumento analítico, idóneo para considerar un fenómeno específico y temporalmente acotado, diferente del proceso histórico de internacionalización (Dicken, 1998; Gereffi et al., 2005).

b) Unidad de análisis: el todo sistémico vs. el abordaje de las cadenas como lonjas sectoriales

En el marco de esa disidencia en el análisis temporal, el segundo elemento que ha distanciado el enfoque de GVC respecto de la TSM tiene que ver con la unidad de análisis y sus propiedades. En la TSM la unidad central de análisis dentro de la larga duración es el capitalismo como sistema. Para ello, las aportaciones de la TSM, y especialmente las contribuciones de Wallerstein, se inscriben en una importante tradición de pensamiento - la hegeliano-marxiana - que adjudica valor estratégico a la idea de totalidad y sostiene, citando a Lukács: "no es la primacía de los motivos económicos en la explicación histórica lo que constituye la diferencia decisiva entre el marxismo y el pensamiento burgués, sino el punto de vista de la totalidad" (Wallerstein, 1974:387).

Esa totalidad, entendida como la unidad desde la que se entienden las partes, no solo expresa en la TSM una afirmación de la realidad sino también una forma de comprenderla. Es decir, la comprensión de la totalidad demanda una unidad disciplinar obligada a superar la escisión trilógica en las ciencias sociales (Wallerstein, 2004a). Bajo ese todo que opera como unidad, se inscriben - y en buena parte se explican - las especificidades de una diversidad de "formas particulares", expresadas en formas de naciones, territorios, actores, Estados, etc. Bajo la TSM, la unidad analítica que expresa ese todo es el sistema-mundo, comprensible como "...zona espacial/temporal que atraviesa muchas unidades políticas y culturales, un sistema que representa una zona integrada de actividad e instituciones que obedecen a ciertas reglas sistémicas" (Wallerstein, 2004b:17). Esa zona espacial/temporal se conforma a partir de un complejo de redes económicas, políticas y culturales sobre el que se edifica una sofisticada división global del trabajo. Es en esa unidad donde se inscriben las cadenas productivas (Hopkins y Wallerstein, 1977), que cumplen un papel fundamental para comprender las delimitaciones de actividades que componen di- 
cha especialización, y vinculan aquellos actores y espacios que operan desarrollando las actividades, decisiones y procesos de valorización a partir de los que se definen los posicionamientos centrales, semiperiféricos y periféricos del sistema-mundo.

Ahora bien, como el sistema y los posicionamientos son el elemento prioritario, las cadenas no pueden ni deben ser comprendidas al margen de estos, puesto que contribuyen a comprender - y demandan ser observadas desde - el todo que explica la dinámica general del sistema y su conformación. En tal sentido, aun cuando el enfoque del todo sistémico presenta la producción y el intercambio como momentos en los que el sistema se despliega, es en el intercambio que el enfoque de la TSM fija una prioridad para entender la forma contradictoria, desigual y expoliativa sobre la que se reproduce el sistema-mundo (Navarro, 1982; Arrighi y Drangel, 1986; Wallerstein, 1974). La noción de cadenas de mercancías contribuye al entendimiento de esa reproducción y esa forma a partir de identificar quiénes controlan las actividades centrales y quiénes se posicionan periféricamente dentro de ellas. Inserta dentro de la comprensión de ese todo, y analizada agregadamente para entender la configuración jerárquica de este - centro, periferia y semiperiferia -, la noción de cadenas de mercancías contribuye a la comprensión del desigual control espacial de actividades que en ellas se despliegan, diferenciándose, como vimos en la primera sección, aquellas actividades centrales - que absorben la mayor parte de los beneficios producidos dentro de la cadena - y periféricas - que sólo se apropian de una porción marginal de los mismos.

En este marco, el enfoque de GVC toma distancia de esa noción de totalidad temporal de larga duración, para detenerse en la comprensión de un proceso singular y temporalmente más delimitado, la globalización. Esta es ahora analizada a partir del examen de cadenas específicas recompuestas sectorialmente. A diferencia de la TSM, que utiliza una perspectiva holística para subsumir la especificidad de las cadenas dentro de la lógica del sistema, la perspectiva de las cadenas globales de valor entiende por holística el desentrañamiento del funcionamiento de una cadena determinada a partir del recorrido de sus distintas fases, observando por arriba sus formas de gobernanza y, por debajo, las oportunidades de mejora (Gereffi y Lee, 2012). La complementariedad de esos dos conceptos esenciales del enfoque, la gobernanza y el ascenso, recae invariablemente sobre ámbitos sectorialmente específicos, con epicentro industrial, brindando una comprensión 
de la realidad a través de "lonjas" sectoriales (Bernstein y Campling, 2006) que se muestran dinámicamente, en toda su extensión espacial y funcional, y en el que se relacionan actores económicos e institucionales de los países centrales y periféricos.

Mientras está claro que la gobernanza pertenece al categorial que viabiliza las formas de dominancia de las grandes firmas que controlan las cadenas, los ascensos son presentados como las formas más (o menos) adecuadas con las que cuentan los actores para cualificar su actividad sectorialmente organizada. De este modo, los conceptos de gobernanza y ascenso no son puestos como marcos a ser analizados para dar cuenta o poner en evidencia una configuración jerárquica y desigualadora, sino como una realidad en la que cabe explorar las formas de integración más adecuadas.

\section{c) Los actores y su dinámica}

Las formas de aproximación a nivel temporal, la unidad de análisis priorizada, así como los aspectos que hacen a la dinámica de esta última, afectan la forma como se concibe la acción y relaciones de los actores en las cadenas globales. En la TSM la inserción en la totalidad contradictoria y de larga duración condiciona la interpretación de la dinámica de los actores a su rol en la reproducción de esa configuración jerárquica y dominante que sustenta la lógica totalizadora del sistema. En otros términos, los actores no son independientes de esa lógica sistémica, sino que se insertan en esta, se explican por, y al mismo tiempo contribuyen a explicar, esa lógica.

Dentro de esa dinámica, el amplio espectro de actores a considerar tiene, en este caso, su punto de partida analítico en el trabajo o la fuerza de trabajo, teniendo en cuenta la definición vertida en la sección anterior de la cadena como red de procesos de trabajo y producción que dan lugar a un producto terminado (Hopkins y Wallerstein, 1986:159). La fuerza de trabajo y los procesos productivos que tienen lugar en la periferia operan en dirección de sustentar la reproducción del centro, pues, como bien remarca Robinson:

...un componente central en la teoría de Wallerstein es la generación y apropiación de los excedentes a lo largo del sistema. Los excedentes tienden a moverse desde la periferia y semiperiferia hacia las regiones centrales, de modo que el funcionamiento natural del sistema - es decir, la acumulación mundial - resulta en el enriquecimiento y el desar- 
rollo del centro y el empobrecimiento y subdesarrollo de la periferia. Aquí vemos cuán importante es el concepto de la división del trabajo en la teoría del sistema-mundo (2011:8).

Nos encontramos ante una teoría que proporciona una explicación de las desigualdades globales y, como muchos han señalado, un potente antídoto contra las teorías de la modernización que proliferaron en los años 1950 y 1960. En la perspectiva de GVC, la dinámica a analizar pasa a ser cuál de las formas de gobernanza y cuáles formas de mejoras se han realizado o resultan potencializables para dar cuenta de una red de empresas dada. Las empresas y dichas redes, y no el trabajo, son quienes asumen la centralidad. De este modo, la relevancia se desplaza del trabajo a las empresas, que pasan a constituir el centro de gravedad en el análisis de las redes globales y quienes expresan las formas en que se conforma la gobernanza y se canalizan determinadas mejoras en diferentes cadenas que se encuentran gobernadas bajo formas específicas. El enfoque avanza, a partir de ello, en la exploración de la capacidad de complementarse y cualificarse al incorporarse en redes que tienen particulares formas de gobernanza.

\section{d) El poder y su vínculo con la dinámica de los actores}

En la TSM, el poder se entiende básicamente como dominación: es la capacidad de imponer voluntad sobre otros que, en el caso de la compleja división del trabajo que conforma el contradictorio sistemamundo capitalista, representan quienes controlan las posiciones centrales de las cadenas de mercancías.

Las cadenas de mercancías trabajan a través de una jerarquía de poder $y$, en el marco de ellas, los actores y espacios que controlan las actividades centrales ejercen su forma dominante para incorporar selectiva y subordinadamente a aquellos que no forman parte de los centros, quienes pasan a depender de ellos en una relación básicamente expoliativa dentro del funcionamiento del sistema-mundo. Esa relación, que incluye múltiples y combinadas formas tanto de coerción como de consenso, se inscribe siempre en un análisis que no hace centro en determinada cadena de mercancías, sino en la compresión del capitalismo como unidad sustentada en una forma jerárquica y desigualadora. Esa relación jerárquica y desigualadora, en donde el poder opera como capacidad de imponer, se viabiliza por la conformación desigual de los Estados, puesto que "...la economía-mundo desarrolla un patrón en el 
que las estructuras del Estado son relativamente fuertes en las áreas centrales y relativamente débiles en la periferia" (Wallerstein, 1976:232).

La conceptualización del poder dentro de la perspectiva de GVC sufre una variación que debe ser entendida en el contexto de cambio del foco de análisis respecto a la TSM. Se podría decir que el enfoque de GVC ha puesto de manifiesto la posibilidad de comprender "...cómo se distribuye y ejerce el poder entre las empresas y otros actores en la cadena" (Sturgeon, 2008:2). Esto significa que posibilita la identificación de quién es el encargado de generar y preservar esas funciones de mayor dinamismo - en términos del control del valor -, es decir, permite ver cómo se distribuye el poder entre las instituciones y los agentes económicos (Gereffi et al., 2005), y qué forma asume el poder en términos de red y gobernanza. En tal identificación y la comprensión de la estructura de funcionamiento de la cadena intervienen los ya considerados conceptos de gobernanza y ascenso.

Mediante el concepto de gobernanza se clasifican las GVC en las ya explicadas cadenas dirigidas por el productor y las dirigidas por el comprador. En el caso de las primeras, la gobernanza se encuentra en una actividad productiva nodal, en cambio, en las segundas, la gobernanza de las cadenas opera bajo la forma de redes verticalmente integradas, donde los costos de información, diseño de la producción y los sistemas avanzados de gestión de la oferta establecen las barreras de entrada. En estas cadenas, las funciones de producción suelen ser subcontratadas y los actores clave se centran en la marca, el diseño y las funciones de marketing. Estas formas de gobernanza no son estáticas y varían de acuerdo a las condiciones históricas. Así, de acuerdo a Gereffi (2001) “...hay una afinidad entre la transición de la estrategia de desarrollo de la ISI a la IOE y el cambio de una cadena de valor dirigida por el productor a una cadena dirigida por el comprador".

Por su parte, en el marco de los diferentes tipos de gobernanza de las cadenas, se introduce el concepto de mejora (upgrading), que procura considerar desde una perspectiva de abajo hacia arriba la capacidad de los actores que se integran subordinadamente a las cadenas para mejorar su condición de generación y captación de valor y, por ende, su posición. Para ello, se evalúan las mejoras en la calidad y diversidad de productos, en la eficiencia para producirlos o en el control de nuevas funciones - de mayor valorización - que aún no controlan. Dentro de 
esas tres formas de asensos o mejoras, la funcional es la que resulta fundamental, puesto que determina la capacidad de ascender al control de las actividades que detentan mayor generación de valor, básicamente, la capacidad de pasar de la producción manufacturera al diseño o comercialización (Gereffi, 1999; Humphrey y Schmitz, 2002).

Aunque estas pautas permiten indicar quién controla la cadena (gobernanza) y cómo pueden integrarse dinámicamente el resto (upgrading), el enfoque dejó un vacío e imprecisión en la concepción de poder. En el marco de la ausencia de definiciones sobre lo que se entiende por poder en el enfoque de GVC, la concepción que vino a llenar ese vacío conceptual provino de la perspectiva de redes, a la cual ha quedado fuertemente vinculado, para resaltar los macro - y micro - aspectos de la organización social que no pueden explicarse desde las relaciones sociales jerárquicas y de mercado (Messner, 2002). Esta incorporación de los conceptos de red al enfoque de GVC se ha hecho a través de la perspectiva de embedded network procedente de la sociología económica y organizacional (Granovetter, 1985), así como del enfoque más reciente de la teoría del actor red (Latour, 2005), con un impacto importante en el pensamiento geográfico y relacional (Allen, 1997).

La influencia de este pensamiento relacional del poder en el análisis de las cadenas globales ha encontrado una atención teórica más explícita a través de los aportes del enfoque de las redes globales de producción, y reemplaza esa idea de poder como "capacidad de acción sobre los demás" - bien presente bajo la TSM - por una que lo entiende como un resultado del "esfuerzo colectivo" desarrollado a partir de las relaciones en red (Hess, 2008). Esta concepción facilita el análisis de las relaciones entre actores a partir de procesos ganar-ganar, que ofrecen un empoderamiento accesible para casi todos los actores involucrados en los esfuerzos colectivos.

Transformado en una perspectiva dominante de conceptos como "gobernanza" y "confianza", y en línea con los esfuerzos de los actores que juegan juegos ganar-ganar, esa noción de poder como coproducción colectiva toma distancia de la explicación de las formas estructurales de dominación que forman parte de la TSM y su análisis de las cadenas de mercancías. De este modo, se alinea con aquellas preocupaciones académicas relacionadas con la forma en que la dinámica local se puede conectar más eficazmente con las redes globales. La conexión se ha realizado a través de la mejora obtenida producto de la cooperación y 
las interacciones a distancia con los actores globales (Humphrey y Schmitz, 2002), y ayuda a avanzar hacia formas de mayor valor añadido a la producción que respondan a los estándares mundiales (LundThomsen y Nadvi, 2010).

La tarea ha encontrado el impulso de un grupo de investigadores agrupados en torno al Institute of Development Studies (Universidad de Sussex), a partir de estudios empíricos desarrollados sobre una multiplicidad de sectores de los países centrales que evalúan el papel de la cooperación entre los actores locales de diferentes conglomerados ubicados en ellos (horizontales) y las relaciones de estos últimos con las firmas líderes (verticales) (Schmitz y Knorringa, 2000; Giuliani et al., 2005). En ellos, se ha intentado dar cuenta de que esa interacción de las firmas agrupadas en clusters bajo relaciones cuasi-jerárquicas pueden experimentar una rápida mejora de productos y procesos (Humphrey y Schmitz, 2002).

Toda esta "gran familia" de defensores y analistas de prácticas - horizontal y verticalmente - cooperativas, dentro de la cual la perspectiva relacional de las redes mundiales y el análisis "territorial" parecen finalmente converger, tiende a asumir como imprescindible para las empresas de los países en desarrollo (especialmente las pequeñas) el integrarse a las cadenas globales, y propone el examen de las formas de hacerlo a partir de interrelaciones y acciones cooperativas en los que no existen juegos de suma cero. Es decir, a partir de la concepción de poder que domina, las formas de arriba hacia abajo y de abajo hacia arriba asumen una perspectiva esencialmente de complementación, en la que se destacan las ventanas de oportunidades - o desafíos - para quienes no gobiernan las cadenas.

\section{Limitaciones del Enfoque de las Cadenas Globales de Valor}

Del análisis comparado entre los enfoques de lsa cadenas globales de valor y la teoría del sistema-mundo no sólo se desprenden relatos y metodologías diferentes, sino también elementos que permiten identificar los límites que presentan estos dispositivos teóricos para analizar los nuevos procesos socioeconómicos y espaciales de la globalización. Asimismo, se permite vislumrar las restricciones estructurales que esa persistente estructura jerárquica norte-sur fija para actores, regiones y naciones del Sur Global. Es decir, al observar comparativamente las dos perspectivas, surgidas en el centro, se puede apreciar las debilida- 
des de la primera para responder a los factores que dan cuenta de la ampliación - y no reversión - de las desigualdades entre el centro y la periferia del sistema-mundo.

La teoría del sistema-mundo, más allá de sus debilidades funcionalistas y deterministas (Skocpol, 1977), contribuye a formular una matriz holística de análisis y comprensión del comportamiento de los actores en el capitalismo y, al "dar a luz" al enfoque de cadenas, lo inserta dentro de esa matriz. Las cadenas de mercancías bajo la TSM hacen centro en la explicación de la reproducción y mantenimiento de las relaciones centro/semiperiferia/periferia en el "período largo" del capitalismo, dentro del cual caben las actuales transformaciones globales. Es decir, su conformación contiene los elementos esenciales para responder temporal y funcionalmente a los factores de larga duración dentro de los que se inscribe el mantenimiento de la estructura jerárquica y desigual del capitalismo. Esta brecha de ampliación de las desigualdades entre los países centrales y la periferia del sistema-mundo puede observarse en el gráfico a continuación, tomando en consideración el indicador del producto bruto per cápita de los países que conforman uno y otro grupo, desde comienzos del siglo XVI hasta nuestros días. Los datos muestran el visible agravamiento experimentado por la estructura jerárquica y el proceso de desigualación del sistema capitalista en la más reciente etapa, a partir de la crisis de modelo fordista-

Gráfico 1

Evolución del PBI per cápita en Dólares Internacionales de 1990

(período 1500-2000)

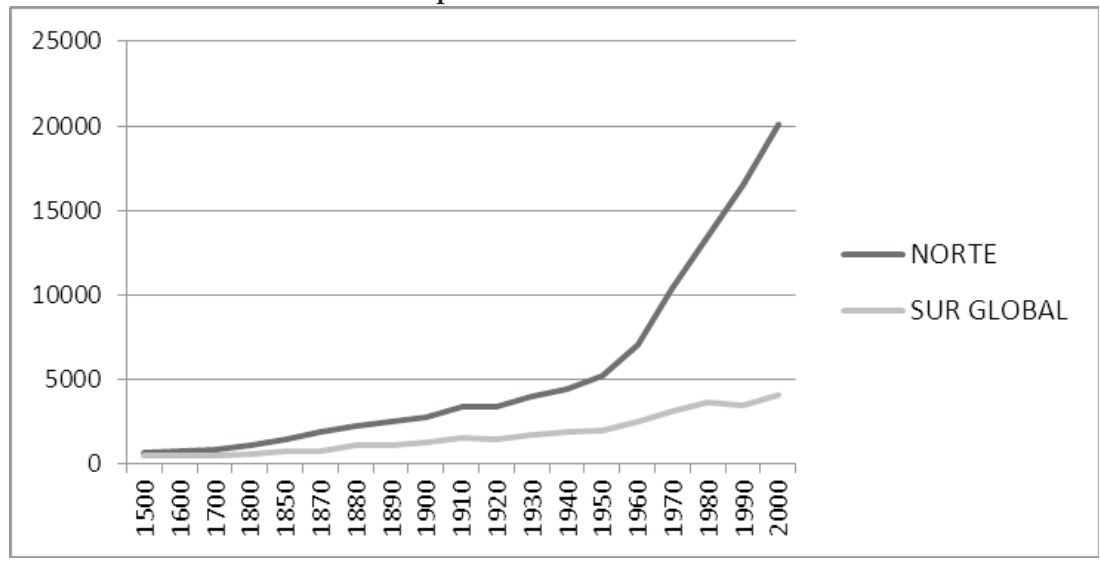

Fuente: Elaboración propia en base a datos de Maddison (2006). 
keynesiano y el proceso que se acentúa a partir del advenimiento del neoliberalismo en los años 1970.

Al distanciarse de la teoría del sistema-mundo, y a pesar de incorporar aspectos conceptuales y metodológicos relevantes para comprender las especificidades del proceso de globalización - que la TSM desestima -, el enfoque de GVC encuentra limitaciones para identificar los factores que explican esa inalterada estructura jerárquica y desigual, esencialmente por quedar circunscripto a un análisis sectorializado del comportamiento de diferentes redes industriales interempresariales consideradas dentro de un acotamiento temporal en el que emerge el proceso de globalización. Dentro de las especificidades de esas redes, como se indicó, la perspectiva de GVC finaliza apelando a una conceptualización del poder como proceso coproductivo que analiza en esa especificidad globalizadora las múltiples formas interactivas en la que los actores empresariales de los países periféricos se articulan o pueden hacerlo con las grandes firmas que lideran las cadenas globales, desarrollando eventuales mejoras a través de esa inserción, o identificando sus restricciones para lograrlo.

En este sentido, la elusión por parte de GVC del poder como dominación y la exclusión del patrón metodológico que apela a la comprensión de ese poder en la reproducción global del sistema capitalista, con su lógica contradictoria y desigualadora, encuentra limitaciones para dar cuenta de dos elementos centrales: a) en primer lugar, ¿cómo se perpetúa en el tiempo esa totalidad contradictoria desde la que se explica el permanente y ampliado proceso de bifurcación entre los países centrales y la periferia en términos de riqueza?; b) en segundo lugar, ¿cómo los actores y redes analizadas sectorialmente reproducen esa lógica estructural?

Los límites teóricos, particularmente en lo que se refiere al concepto de poder y al papel de los actores en las redes de empresas que forman su objeto de estudio, impiden comprender cómo la continuidad expuesta en el punto (a) - resaltada en la TSM - se expresa en la reproducción plasmada en el punto (b). De esta manera, su marco conceptual - y la metodología de análisis propuesta - conlleva un ocultamiento de las razones de subordinación y la continuidad de la lógica histórica de reproducción del capitalismo. A su vez, ese marco conceptual condiciona su propia indagación empírica, la que, aunque orientada a considerar las potencialidades para los ascensos de los actores del Sur Global, 
finalmente da cuenta de las distintas formas de integración subordinada de los países periféricos y la captación preferencial. Un gran número de estudios dentro del enfoque de GVC realizados en los países en desarrollo ha mostrado las asimetrías que surgen de la creciente concentración de poder por parte de los grandes actores - comerciales o productivos -, quienes controlan las funciones más dinámicas de las cadenas, sobre todo aquellas relacionadas con el marketing y el diseño y los límites que ello presenta para la mejora funcional que conduce al control de esas actividades.

Por lo tanto, a pesar de la centralidad en los ascensos de los actores de los países periféricos, los propios estudios realizados al interior del enfoque de GVC no hacen sino reconocer el selectivo control de las competencias centrales por parte de las grandes empresas globales, y, a partir de ello, la reafirmación del papel asimétrico, subordinante y estructuralmente limitante de quienes se intentan incorporar a través de los mejoras asociativas. El abrumador mantenimiento de la localización de esas empresas globales (con sus funciones) en los países centrales refleja a un nivel agregado la estructura asimétrica sobre la que se reproduce el capitalismo: en los últimos veinte años, el promedio de participación de las empresas trasnacionales de los países centrales en las principales cien a nivel mundial es cercano al 98\% (Unctad, 2011).

A raiz del desconocimiento de este aspecto y sus efectos por parte del enfoque de GVC, no resulta irrelevante el mencionado desplazamiento de la concepción del poder como dominación sostenido desde la TSM, y su reemplazo por otra basada en procesos de construcción colectiva y juegos ganar-ganar (Hess, 2008). Esa lógica de análisis del poder y la des-argumentación sobre los aspectos empíricamente no resaltados de la dominación convive con la ausencia de una perspectiva holística y sistémica del capitalismo, necesaria para reconocer cómo se insertan las relaciones de dominación entre los actores de las cadenas y se reproducen las formas estructuralmente desigualadoras y la jerarquía espacial altamente rígida del proceso de acumulación que divide el norte y el sur. Ello, en conjunto, es lo que viabiliza la asimilación del cuerpo teórico de GVC por parte de los organismos internacionales y el despliegue a través de ello de un dispositivo neoliberal de intervenciones y financiamiento institucional que refuerza - más que altera - esa estructura de reproducción e integración (Fernández, 2015).

Sin lugar a dudas, la distancia que han tomado los investigadores de GVC respecto a los teóricos del sistema-mundo ha contribuido a la 
construcción de muchas de sus principales limitaciones. En este marco, la recuperación de esa desplazada concepción del poder y su reconexión con el análisis del comportamiento estructural y sistémico del capitalismo - como lo hace la TSM - resultan fundamentales para comprender las estrategias y restricciones, ya no solo de las empresas, sino de trabajadores e instituciones posicionados en el Sur Global. Es solo a través del reconocimiento de este terreno que la concepción coproductiva del poder que domina el enfoque de GVC podría ganar sentido para los actores subalternos o excluidos de la periferia del sistemamundo, jugando un papel complementario - no central - en la reversión de los procesos de subordinación que pueden leerse al recuperar aquella perspectiva del poder como dominación.

De todos modos, la recuperación de los aportes de la TSM para la comprensión de las cadenas globales en la estructura de funcionamiento del capitalismo como un todo sistémico contiene, a su vez, deficiencias que comparte con el enfoque de GVC a la hora de explicar la nueva reconfiguración económica global que tiene lugar desde finales del siglo $\mathrm{XX}$.

\section{CONVERGENCIAS TEÓRICAS Y CONCRECIONES EMPÍRICAS: TRAYECTORIAS NACIONALES, ESTADO Y LA EMERGENCIA DEL SUR GLOBAL}

A través de la diferenciación dilucidada anteriormente se intentó mostrar cómo la divergencia entre uno y otro dispositivo teórico afecta la forma en que se analizan procesos empíricos. Esto deja las puertas abiertas a la funcionalización del dispositivo analítico a la reproducción - y no a la explicación - de la estructura jerárquicamente desigualadora del capitalismo y a su asimilación. No obstante, la superación de ese alejamiento a partir de la reasociación entre las cadenas globales de valor y la teoría del sistema-mundo, para recuperar la perspectiva holística y contradictoria del capitalismo y situar el poder como dominación, no permite dar cuenta de: a) la supresión de las unidades nacionales y, por lo tanto, del complejo de elementos que conforman las trayectorias nacionales sobre las que se configuran, también en la periferia, trayectorias diferenciadas; b) la complejidad del Estado como elemento central para explicar no sólo la reproducción global del capitalismo, sino también las especificidades de esas trayectorias; c) las dinámicas regionales y macrorregionales diferenciadas que dan lugar a cambios macroeconómicos, como la emergencia del Sur Global. 


\section{La Supresión de las Unidades/Trayectorias Nacionales}

Por diferentes razones, la TSM y el enfoque de GVC contienen una eliminación o desplazamiento del Estado-nación como unidad de análisis, con tal extensión que tanto naciones como Estados pasan a ser elementos subalternos - cuando no marginales - en los registros discursivos de los mismos.

En la TSM, la dinámica del sistema no puede explicarse desde unidades particulares, sino, como vimos, desde una totalidad configurada por el sistema capitalista analizado como un todo desde donde se despliega una lógica que explica el posicionamiento de las naciones y sus Estados y no viceversa. La dinámica histórica de la acumulación capitalista a escala global fortalece una estructura centro-semiperiferiaperiferia dentro de la cual las unidades nacionales se insertan y requieren ser analizadas. Más aún, los Estados-nación y las unidades nacionales a las que pertenecen se insertan dentro de macrorregiones estructuralmente atadas a una lógica general que reproduce, con escasas alteraciones, un sistema de estratificación formado por regiones dominantes y otras periféricas (Chase-Dunn y Anderson, 2005). En tal contexto, las unidades nacionales y sus Estados no son explicantes de sino explicados por su referencia al sistema-mundo en el que se insertan. Dicho sistema configura una red desigualadora de actuación que escapa al control de las entidades políticas menores, a las cuales trasciende, para desplegar una lógica global que moldea la dinámica institucional nacional y marca la división entre Estados fuertes (en los centros) y débiles (en la periferia) (Wallerstein, 1974).

La desaparición de las unidades nacionales es compartida por el enfoque de GVC y conforma, de hecho, una de las debilidades más visibles de la misma. En este caso, no es el posicionamiento desde un sistema globalmente dinámico y contradictorio que explica desde el todo el comportamiento de sus partes, sino su abrumador enfoque en la empresa (Bair, 2008) y las redes empresariales, en el que se exploran sus actividades, formas de relacionarse, cambios funcionales, distribución del valor $\mathrm{y}$, finalmente, sus formas de gobierno a escala mundial.

Ese aferramiento al análisis interno de la red empresarial configurante de la cadena, no obstante reconocer el carácter "situacionalmente específico, socialmente construido y localmente integrado" (Gereffi et al., 1994:2), deriva en la investigación empírica y en la agenda propuesta desde el enfoque de GVC en una muy menguada importancia a las tra- 
yectorias nacionales en cuyo marco las empresas y sus relaciones se desarrollan.

La irrelevancia dada a esas trayectorias, en el caso de la TSM por la subsunción de la dinámica nacional dentro del sistema-mundo, y en el caso del enfoque de GVC por concentrarse en el complejo de relaciones interempresariales a escala global, revela restricciones para explicar apropiadamente cómo y por qué regiones y países específicos podrían haber sido afectados por una cadena específica; y a la inversa, cómo las cadenas afectan y son afectadas por esos procesos regionales y nacionales.

Pese al reconocimiento de algunos exponentes del enfoque de las Redes Globales de Producción acerca de lo pertinente de "concebir la constitución nacional o incluso local de las cadenas que operan geoeconómicamente a varias escalas espaciales..." (Smith et al., 2002:50), ello no resulta suficiente para explicar cuáles son las repercusiones de evaluar este contexto de trayectorias nacionales de las cadenas de valor. Esencialmente, esto significa la necesidad de considerar la forma bajo la cual determinadas estructuras y dinámicas socio-económicopolíticas, históricamente conformadas, condicionan los modos en los que las cadenas globales penetran o se desarrollan en un determinado espacio (ya sean países o regiones en vías de desarrollo), y la forma en la que impactan en el conjunto de actores económicos e institucionales.

\section{La Relevancia del Estado (Nacional) en la Configuración de las Trayectorias Nacionales y sus Variedades}

Mientras que las trayectorias nacionales son omitidas en la TSM como unidades de análisis, el Estado - y en particular los Estados nacionales -, han sido posicionados funcional y subordinadamente respecto de la interpretación holística, sistémica y contradictoria que forma su estructura analitica. Bajo esta óptica, el sistema, una vez establecido, hace que todo los elementos refuercen lo demás (Skocpol, 1977). La funcionalidad del Estado a dicha estructura se expresa en una divisoria, bastante esquemática, entre "Estados fuertes" que refuerzan el centro del sistema-mundo - y aseguran a través del soporte extraeconómico la extracción y retención de plusvalía -, y "Estados débiles", subalternamente posicionados, que operan como facilitadores de la relación centro-periferia (Wallerstein, 1974). Sin entrar en conflicto con esa interpretación, otras contribuciones desarrolladas dentro de la frontera de la TSM han brindado sofisticación al análisis del involucra- 
miento estatal, al dar cuenta del papel central e irremplazable del Estado en el armazón de la compleja trama de relaciones entre la reproducción cíclica y hegemónica del capital, y su expansión y control del territorio (Arrighi, 1999).

Sin embargo, observada en su conjunto, la TSM hace participar al Estado más bien como una pieza subordinada a las condiciones fijadas por la lógica jerarquizadora y desigual que impone el sistema-mundo, en estrecha relación con lo que sucede en respecto de las trayectorias nacionales y sus especificidades. Bajo esa presencia estatal, analizada a través de una conformación e implicación binaria (Estado fuerte o débil) en función de los requisitos y pautas que impone el funcionamiento general del sistema-mundo, no existe capacidad para entender cómo, a partir de Estados configurados nacionalmente, emergen procesos relevantes y específicos para entender la lógica general que conforman los procesos globales (Skocpol, 1977). Lo admitido son entidades estatales fuertes o débiles que finalmente subordinan todas sus particularidades a una lógica sistémica, organizada a través de una multiplicidad de cadenas globales de mercancías, siempre jerárquicamente ordenadas desde un centro, una periferia y una semiperiferia amortiguadora.

A su vez, las restricciones de esa incorporación del Estado en la TSM se amplían visiblemente en el enfoque de GVC, como resultado de estar ya no simplemente subsumido en la lógica sistémica, sino directamente ausente como dispositivo analítico (Nielsen, 2014; Fernández, 2015). En este sentido, el enfoque de GVC difundido por Gereffi y los demás colegas mencionados confluye, en primer lugar, con ciertas lecturas de la globalización en su restricción para identificar las complejas intersecciones que experimentan actualmente las dinámicas globales y los Estados nacionales al configurar la realidad actual, así como el modificado pero persistente y estratégico papel que le cabe aún a este último (Peck y Tickell, 1994; Jessop, 1999). Y en segundo lugar, cómo esos Estados y las diferenciadas calidades de sus estructuras contribuyen a conformar en los escenarios nacionales e incluso macrorregionales diferentes variedades de capitalismo (Gray, 1999), representativas de un heterogéneo mosaico de respuestas y performances dentro del proceso globalizador (Rodrik, 2011).

Al obturar la posibilidad de observar esas variedades en las configuración de los procesos globales, el enfoque de GVC pasa a integrar el club 
de aquellos análisis impedidos de identificar las causas de las diferentes performances y configuraciones nacionales que tensionan con los procesos globales (Rodrik, 2011), así como dentro de ello, las capacidades nacionalmente diferenciadas de enfrentar las restricciones y capitalizar las habilitaciones que acompañan ese proceso (Weiss, 2003).

Por otro lado, al suprimir esas variedades y el involucramiento del Estado con las trayectorias históricas bajo las que se conforman, el enfoque de GVC queda desconectado de una rica literatura en el campo de la sociología y la economía política comparada que observa, particularmente al interior del Sur Global, la forma en que las estructuras estatales - históricamente conformadas - sellan diferenciadas capacidades de articulación con los procesos globales, a partir del desarrollo de estructuras productivas orientadas por el Estado (Evans, 1995; Kohli, 2004; Chibber, 2003). Todos estos aportes cuestionan el homogeneizador e irrealista proceso autorregulatorio promocionado bajo el Consejo de Washington y el mainstream económico, a la vez que contribuyen a reposicionar la ineludible dialéctica Estado y mercado que configura el capitalismo y sus variedades (Diniz, 2011). Asimismo, discuten con enfoques como el de GVC y los insta a sumar al Estado y sus capacidades - desarrolladas a partir de determinadas trayectorias nacionales - para explicar, como consideraremos seguidamente, el diferencial dinamismo del Sur Global y las variedades capitalistas que existen en su interior.

\section{Las Dinámicas (Macro)Regionales y la Emergencia del Sur Global}

La convergente desafectación que la TSM y GVC hacen tanto respecto de las trayectorias nacionales como del Estado y las diferentes configuraciones del capitalismo que este contribuye a conformar, coloca a ambos enfoques ante limitaciones para dar cuenta del proceso de emergencia del Sur Global.

En lo que respecta al primer aspecto, y por el lado de la TSM, las trayectorias nacionales aparecen disueltas en la prioridad analítica dada a la totalidad contradictoria del capitalismo. En su marco teórico, la periferia forma parte de una inalterada e inalterable dinámica global y, de esta manera, dicho proceso de contradicción se reproduce y potencia. Estudios como los de Arrighi y Drangel (1986) admiten que cambios de carácter individual pueden tener lugar dentro de la jerarquía de riquezas que estructura la economía mundial - un ascenso individual -, 
pero, por lo analizado, su dispositivo teórico no contiene elementos que den respuesta al porqué del mayor dinamismo comparado del gran área representativa de la periferia, es decir todo el Sur Global.

El Estado, como observamos, opera funcionalmente y reductivamente en unos casos como "Estados fuertes", que apuntalan las actividades centrales de las cadenas en el centro, y en otros casos como "Estados débiles", que adecúan funcionalmente la periferia a los requerimientos extractivos y expoliativos del centro, reproduciendo un esquema desigualador y polarizador que carece de capacidad de alteración estructural. Sin embargo, como puede verse en el siguiente gráfico, en términos de participación en la generación de riquezas, el Sur Global ostenta un marcado proceso de convergencia con los países centrales.

Ante la limitación de la TSM para dar cuenta de esta realidad, el enfoque de GVC no expresa alternativas superadoras, más aun, parece alejarse de ellas desde el momento que aboca su análisis sobre sectores o actividades específicas, sujetas a la consideración de las relaciones interempresariales. Tanto su distanciamiento con la TSM que lo inhabilita para un análisis del sistema en su totalidad como su compartida desconsideración del análisis de las unidades nacionales - y en ello las particularidades y calidades diferenciadoras de los Estados - privan el enfoque de GVC de alternativas analíticas para abordar un proceso agregado de tal magnitud.

Gráfico 2

Evolución de la Participación en el PBI Global por Bloque de Países en Términos de Paridad de Poder Adquisitivo en Dólares de 2005

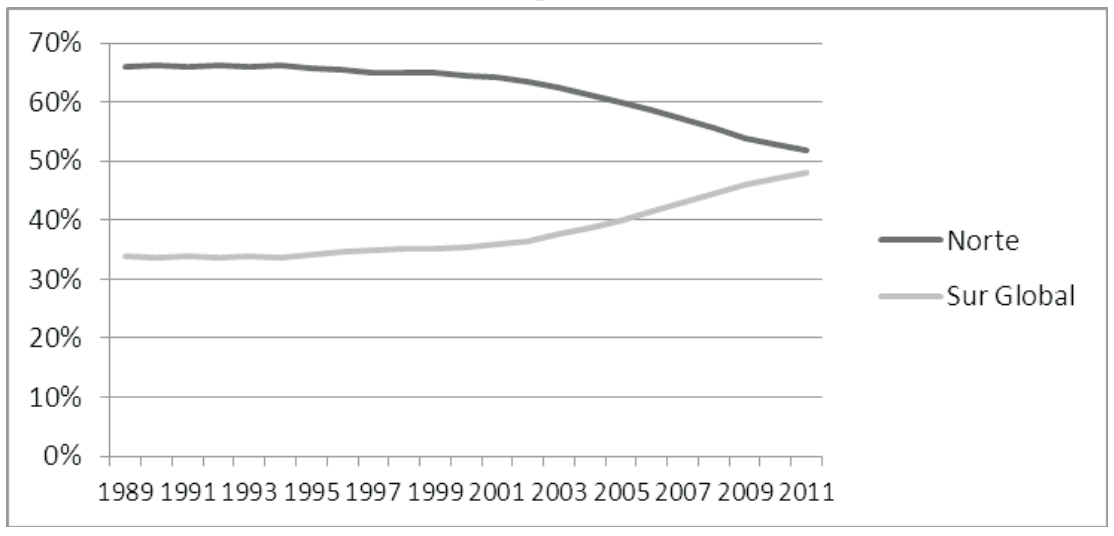

Fuente: Elaboración propia en base a datos del Banco Mundial. 


\section{Gráfico 3}

Empresas Transnacionales no Financieras dentro de las 500 Principales

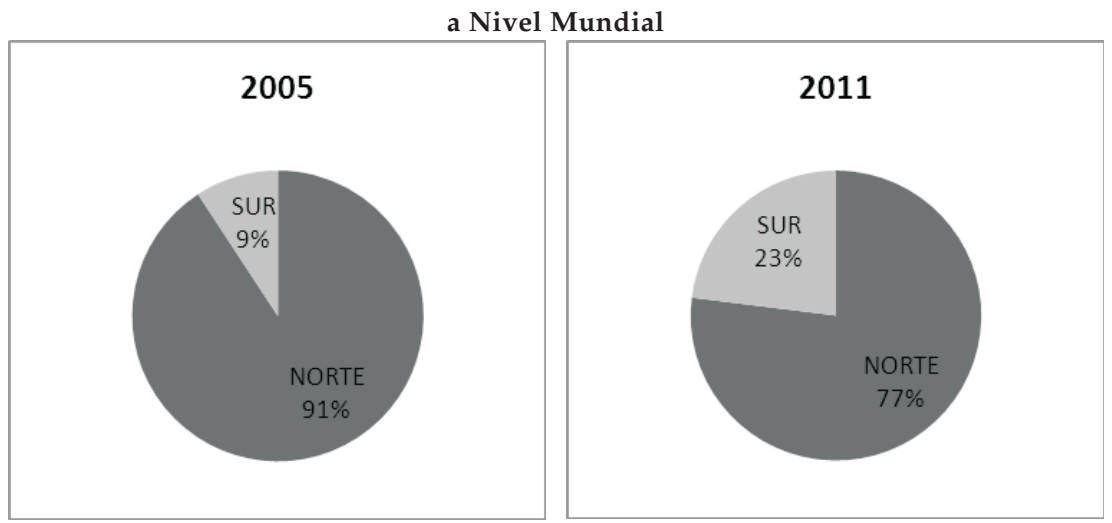

Fuente: Elaboración propia en base a datos de Fortune Global 500.

Aun bajo esas limitaciones, podría argumentarse que ese dinamismo del Sur Global obedece a un progresivo posicionamiento en el control de las actividades de más alta valorización de las cadenas de valor a nivel mundial, particularmente desde la segunda parte de la primera década del naciente siglo, lo cual, como se indicó, tiene su correlato en la cantidad de empresas trasnacionales con origen en los países centrales y en los países periféricos. Lo dicho queda reflejado en el Gráfico 3, donde se compara la participación de los países centrales y los periféricos en las 500 compañías más importantes del mundo.

Sin embargo, el enfoque de GVC no tiene capacidad para explicar desde su instrumental las razones de ese reposicionamiento de las empresas transnacionales de la periferia, vista como un todo, en el sistema mundial. Es decir, no contiene los elementos mediadores que hemos traído a consideración para dar fundamento a la formación diferenciada de dinámicas macro-regionales (supranacionales), y, en su seno, al selectivo y creciente dinamismo de un conjunto de actores estratégicos, esencialmente las empresas transnacionales y sus cadenas. Con escasas excepciones (Linden et al., 2009), los abordajes de la perspectiva de GVC han tenido limitaciones para precisar y resaltar la significación de los anclajes nacionales de determinadas funciones estratégicas. No obstante ello, resulta poco plausible explicar aisladamente y desde la exclusividad de la lógica interempresarial, que excluye las trayectorias nacionales y las diferenciada y diferenciantes configuraciones y calidades de los Estados nacionales, ese reciente y generaliza- 
do crecimiento de las empresas transnacionales del este asiático respecto tanto de los países centrales como del resto del propio Sur Global $^{8}$.

Dar cuenta de ello demanda considerar las particularidades del proceso de conformación macrorregional que tiene como punto de partida la configuración de estrategias nacionales progresivamente difundidas a partir de la transferencia internacional de procesos de sustitución de importaciones y difusión de aprendizajes (Kojima, 2000). Esa arquitectura, en la que se articulan dimensiones nacionales y macrorregionales, ha sido definitoria para el desarrollo de un ambiente económico, institucional y espacial dentro del cual se consolidó un proceso de crecimiento sostenido, con epicentro en el comportamiento manufacturero (ver Gráficos 4 y 5), así como para una inserción global en las actividades más dinámicas tecnológicamente (Gráficos 6 y 7).

\section{Gráfico 4}

Tasa de crecimiento del PBI (promedio 1970-2012)

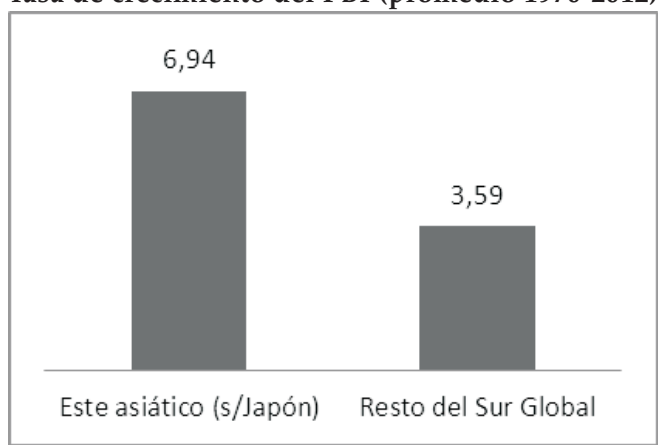

Fuente: Elaboración propia en base a datos de Unctad.

\section{Gráfico 5}

Evolución del PBI industrial sobre el PBI total (1970-2012)

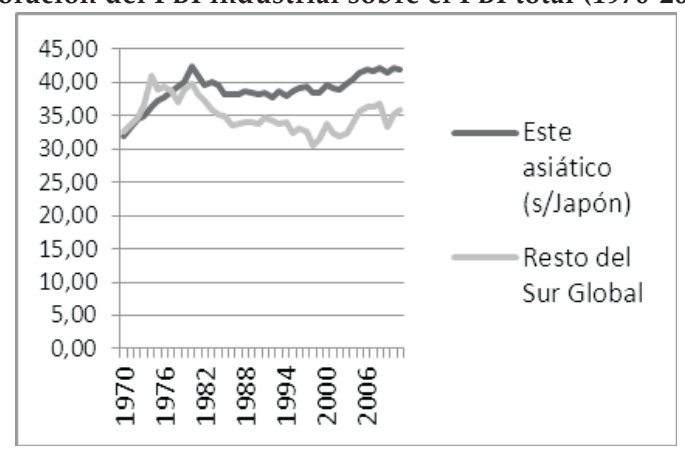

Fuente: Elaboración propia en base a datos de Unctad. 


\section{Gráfico 6}

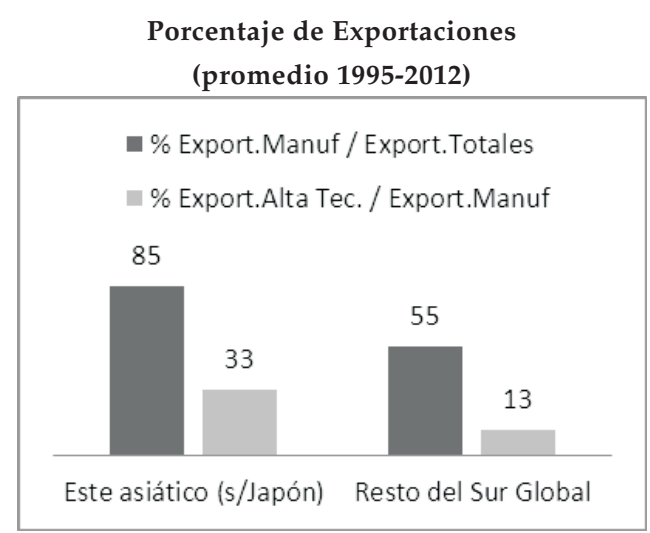

Fuente: Elaboración propia en base a datos del Banco Mundial.

Gráfico 7

Exportaciones de Productos Alta Tecnología Billones de Dólares de EEUU a Precios Actuales

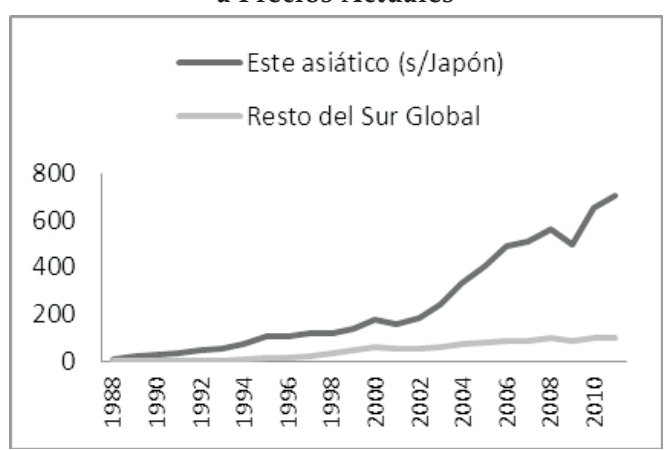

Fuente: Elaboración propia en base a datos del Banco Mundial.

El comportamiento del este asiático en dichas variables, con tasas promedio sensiblemente superiores a las del resto del Sur Global, lo ha posicionado no sólo como un área específica y diferenciada, sino como el motor efectivo del más reciente proceso de dinamización de toda esta gran área periférica del sistema capitalista.

La producción de estos resultados diferenciales, que incluye la capacidad de generar endógenamente en el Sur Global empresas trasnacionales que ocupan posiciones dominantes en las cadenas globales, tiene como basamento el exitoso proceso de industrialización y desarrollo tardío de la región asiática. Una rica y destacada bibliografía, proveniente tanto de la economía política (Amsden, 1989; Wade, 1990; Chang, 
2006;), como de la sociología política (Evans, 1995; Chibber, 2003; Kohli, 2004), ha dado cuenta de cómo en esta área del sistema capitalista mundial, en contraste con el resto del Sur Global, han alcanzado efectividad estrategias nacionales sustentadas en un activo y estratégico papel del Estado, sustentado internamente en sus calidades weberianas y externamente - bajo una circunstancia geopolítica específica y excepcional (Glassman, 2011) - en una interacción virtuosa pero también disciplinante con los actores capitalistas locales que apuntalan el proceso de acumulación. Ha sido sobre la base de estos aspectos que ha ganado viabilidad la salida excepcional de los posicionamientos periféricos de un reducido grupo de países del este asiático (Arrighi y Drangel, 1986), así como la referida conformación macrorregional. Sin embargo, la analizada exclusión - compartida con la TSM de las unidades nacionales y las trayectorias, estrategias y procesos que tienen lugar en su interior y que afectan las dinámicas de inserción global de las empresas en las cadenas globales, impide al enfoque de GVC actuar explicativamente sobre las diferenciadas trayectorias al interior del Sur Global y, en tal contexto, dar cuenta de ese complejo de elementos - de matriz nacional y macrorregional - involucrados en la diferencial capacidad de conformar empresas líderes que viabilizan la inserción en las cadenas globales del este asiático respecto del resto de la periferia.

En definitiva, para convertirse en un instrumento efectivo de análisis y eventualmente de elaboración estratégica para impulsar el desarrollo, el enfoque de las cadenas globales de valor requiere recuperar su capacidad explicativa a partir de enfrentar un doble desafío. Por un lado, de acuerdo a lo considerado oportunamente, el de superar el distanciamiento respecto de la TSM en lo que refiere al reconocimiento de la inserción de los encadenamientos dentro una estructural global y asimétrica, que reproduce formas de dominación dentro de la cual caben las eventuales mejoras de los actores económicos del Sur Global. El segundo desafío, analizado en las líneas anteriores, conlleva la recuperación de una perspectiva analítica capaz de reconocer la importancia de las dinámicas nacionales y la especificidad diferenciadora que asume la conformación de los Estados para comprender la particularidad de los procesos de integración macrorregional y, en dicho contexto, considerar efectivamente los fundamentos por los cuales determinadas áreas del Sur Global se dinamizan diferencialmente, y logran, como el este asiático, obtener progresiva y selectiva capacidad de configurar firmas líderes trasnacionales que ocupan posiciones no subordinadas en las 
redes globales. Es decir, la inserción internacional a través de las cadenas de valor se realiza bajo condiciones compatibles con la endogeneidad de los procesos de innovación y control de las actividades de mayor valorización.

\section{CONCLUSIÓN}

Los argumentos desarrollados en este artículo no tienen como propósito la relativización, ni mucho menos el desconocimiento de las contribuciones del debate sobre las cadenas globales de valor, sino la necesaria advertencia sobre sus restricciones. Éstas, al tiempo que viabilizan su utilización como dispositivo institucional neoliberal por parte de las organizaciones supranacionales, impiden su conversión en una herramienta efectiva que permita comprender la complejidad multiescalar de los actuales procesos de reestructuración global y el juego de intereses que acompaña a la dinámica de subordinación y exclusión del capitalismo.

Si pensamos el escenario latinoamericano, es fundamental desarrollar una reformulación teórica y metodológica del enfoque de las cadenas globales de valor, capaz de sumar y articular los aspectos aquí observados para obtener una comprensión más precisa de las nuevas y crecientes relaciones sur-sur. Esa nueva conceptualización debe asumir como desafío central poner en diálogo campos teóricos hasta ahora precariamente conectados, tales como aquellos que analizan los procesos de la globalización a través de cadenas globales y abordan la inserción global junto con el desarrollo a partir de las dinámicas internas de las trayectorias nacionales y el papel del Estado.

La recuperación critica de las contribuciones de la teoría del sistemamundo aquí realizada para analizar el desarrollo de esos procesos globales, propone entender las transformaciones cualitativas introducidas por el enfoque de las cadenas globales de valor en el marco de una perspectiva holística. Este movimiento conceptual contribuye a subrayar la lógica contradictoria y desigual que acompaña la reproducción del capitalismo observado en su conjunto, así como a interpretar las trayectorias nacionales y el posicionamiento del Estado dentro de la dinámica conflictiva que abre dicha lógica.

(Recebido para publicação em novembro de 2013)

(Reapresentado em junho de 2014)

(Aprovado para publicação em janeiro de 2015)

DADOS - Revista de Ciências Sociais, Rio de Janeiro, vol. 58, nํ 2, 2015 


\section{Víctor Ramiro Fernández y Manuel Facundo Trevignani}

\section{NOTAS}

1. A lo largo del trabajo se utilizará las siglas en inglés para aludir al término "cadenas globales de valor" debido a su difusión generalizada.

2. La noción de Sur Global es un concepto emergente en la academia anglosajona y la acción política institucional del centro (véase Mohanty, 2003; Sheppard y Nagar, 2004). En este trabajo lo hemos adoptado en un sentido comprensivo para referirnos al espacio donde el capitalismo y su compleja red política global opera a través de la exclusión de sus actores respecto de las cadenas globales. Esa subalternización se produce debido a que las actividades centrales y más dinámicas permanecen fuera de ese espacio periférico, situándose en el centro del sistema-mundo visto en su conjunto. En este sentido, la actual división norte-sur guarda mayor relación con la estructura centro-periferia en el marco de la teoría de la dependencia, dado que no tiene que ver con fronteras geográficas sino que hace referencia a las históricas y actuales divisiones de trabajo y riqueza que han llevado al desarrollo desigual y a las divisiones socio-espaciales que se construyen a través de este proceso. En virtud de lo dicho, a lo largo del trabajo las denominaciones "Sur Global" y "países periféricos" encuentra traducción empírica en el resto de los países del sistema-mundo por fuera de Estados Unidos, Europa Occidental, Japón y aquellos pertenecientes a la Mancomunidad de Naciones. Esa disquisición se encuentra relacionada con el nivel de ingreso medio de sus habitantes, considerado como indicador indirecto de la posición en la jerarquía de riqueza de un país dentro del sistema-mundo (Fernández, Lauxmann y Trevignani, 2014).

3. Si bien esta teoría cuenta con múltiples exponentes (Chase-Dunn, Arrighi, Silver, Abu-Lughod, etc.), la formulación principal del enfoque proviene de los trabajos seminales de I. Wallerstein $(1974 ; 1976)$.

4. No obstante, hay una gran discusión (tanto al interior de los teóricos del sistema-mundo como en otros ámbitos) en torno a la existencia y función de la denominada semiperiferia, y las dificultades en cuanto a su conceptualización y medición (Boles, 2002; Lee, 2009; Robinson, 2011).

5. “Mientras que 'internacionalización' refiere a la dispersión geográfica de las actividades económicas a través de las fronteras nacionales, 'globalización' implica una coordinación e integración funcional de esas actividades internacionalmente dispersas" (Gereffi et al., 2005:78).

6. Las citas textuales en el presente trabajo son traducciones propias de los autores.

7. Véase el sitio web www.globalvaluechains.org.

8. Así, el fuerte crecimiento de las empresas transnacionales del Sur Global en el último lustro se explica principalmente por el dinamismo del este asiático, desde donde provienen 84 de las principales 500 firmas frente a 18 del resto de los países periféri$\cos$ (Fortune, 2012). 


\section{Cadenas Globales de Valor y Desarrollo}

\section{BIBLIOGRAFÍA}

ALLEN, John. (1997), "Economies of Power and Space”, in R. Lee y J. Wills (eds.), Geographies of Economies. London, Arnold, pp. 59-70.

AMSDEN, Alice. (1989), Asia's Next Giant. New York, Oxford University Press.

ARRIGHI, Giovanni. (1999), El Largo Siglo XX. Madrid, Akal.

y DRANGEL, Jessica. (1986), “The Stratification of the World-economy: An Exploration of the Semiperipheral Zone”. Review, vol. 10, no 1, pp. 9-74.

BAIR, Jennifer. (2005), "Global Capitalism and Commodity Chains: Looking Back, Going Forward". Competition E Change, vol. 9, № 2, pp. 153-180.

(2008), “Analysing Global Economic Organization: Embedded Networks and Global Chains Compared". Economy and Society, vol. 37, no 3, pp. 339-364.

BERNSTEIN, Henry y CAMPLING, Liam. (2006), "Commodity Studies and Commodity Fetishism II: Profits with Principles'?". Journal of Agrarian Change, vol. 6, no 3, pp. 414-447.

BOLES, Elson E. (2002), "Critiques of World-systems Analysis and Alternatives: Unequal Exchange and Three Forms of Class Struggle in the Japan-US Silk Network, 1880-1890". Journal of World-Systems Research, vol. 7, no 2, pp. 150-212.

CHANG, Ha-Joon. (2006), The East Asian Development Experience: The Miracle, the Crisis and the Future. New York, Zed Books.

CHASE-DUNN, Christopher y ANDERSON, Eugene N. (2005), The Historical Evolution of World-Systems. England, Palgrave Macmillan.

CHIBBER, Vivek. (2003), Locked in Place. State Building and Late Industrialization in India. United Kingdom, Princeton University Press.

COE, Neil y HESS, Martin. (2005), "The Internationalization of Retailing: Implications for Supply Network Restructuring in East Asia and Eastern Europe". Journal of Economic Geography, vol. 5, no 4, pp. 449-473.

DICKEN, Peter. (1998), Global Shift: Transforming the World Economy. (3a ed.). New York, Guilford Press.

et al. (2001), "Chains and Networks, Territorial and Scales: Towards a Regional Framework for Analyzing the Global Economy". Global Network, vol. 1, no2, pp. 89-112.

DINIZ, Eli. (2011), “Depois do Neoliberalismo. Rediscutindo a Articulação Estado e Desenvolvimento no Novo Milênio", in R. R. Boschi (ed.), Variedades de Capitalismo, Política e Desenvolvimento na América Latina. Belo Horizonte, UFMG Editora, pp. 31-55.

EVANS, Peter. (1995), Embedded Autonomy: States and Industrial Transformation. Princeton, Princeton University Press.

FERNÁNDEZ, Víctor R. (2015), "Global Value Chains in Global Political Networks: Tool for Development or Neoliberal Device?". Review of Radical Political Economics, vol. 47, no 2, pp. 209-230.

DADOS - Revista de Ciências Sociais, Rio de Janeiro, vol. 58, nํ 2, 2015 


\section{Víctor Ramiro Fernández y Manuel Facundo Trevignani}

; LAUXMANN, Carolina y TREVIGNANI, Manuel. (2014), “Emergencia del Sur Global. Perspectivas para el Desarrollo de la Periferia Latinoamericana". Economia e Sociedade, vol. 23, no 3, pp. 611-643.

GEREFFI, Gary. (1994), “The Organization of Buyer-driven Global Commodity Chains: How US Retailers Shape Overseas Production Networks", in G. Gereffi y M. Korzeniewicz (eds.), Commodity Chains and Global Capitalism. Westport, Praeger, pp. 95-122.

. (1999), "International Trade and Industrial Upgrading in the Apparel Commodity Chain". Journal of International Economics, vol. 48, pp. 37-70.

. (2001), "Beyond the Producer Driven/Buyer-driven Dichotomy. The Evolution of Global Value Chains in the Internet Era". IDS Bulletin, vol. 32, no 3, pp. 30-40.

(2013), "Global Value Chains in a post-Washington Consensus World". Review of International Political Economy, vol. 21, no 1, pp. 9-37.

; KORZENIEWICZ, Miguel y KORZENIEWICZ, Roberto. (1994), “Introduction: Global Commodities Chains", in G. Gereffi y M. Korzeniewicz (eds.), Commodity Chains and Global Capitalism. Westport, Praeger, pp. 1-14.

GEREFFI, Gary; HUMPHREY, John y STURGEON, Timothy. (2005), "The Governance of Global Value Chains". Review of International Political Economy, vol. 12, no 1, pp. 78-104.

GEREFFI, Gary y LEE, Joonkoo. (2012), "Why the World Suddenly Cares about Global Supply Chains". Journal of Supply Chain Management, vol. 48, no 3, pp. 24-32.

GIBBON, Peter y PONTE, Stefano. (2005), Trading Down: Africa, Value Chains and the Global Economy. Philadelphia, Temple University Press Policy.

GIULIANI, Elisa; PIETROBELLI, Carlo y RABELLOTTI, Roberta. (2005), “Upgrading in Global Value Chains: Lessons from Latin American Clusters". World Development, vol. 33, no 4, pp. 549-573.

GLASSMAN, Jim. (2011), “The Geo-political Economy of Global Production Networks”. Geography Compass, vol. 5, no 4, pp. 154-164.

GRANOVETTER, Mark. (1985), “Economic Action, and Social Structure: The Problem of Embeddedness". American Journal of Sociology, vol. 91, no 3, pp. 481-510.

GRAY, John. (1999), Falso Amanhecer, os Equívocos do Capitalismo Global. Rio de Janeiro, Record.

HENDERSON, Jeffrey et al. (2002), "Global Production Networks and the Analysis of Economic Development". Review of International Political Economy, vol. 9, no 3, pp. 436-464.

HESS, Martin. (2008), "Governance, Value Chains and Networks: An Afterword". Economy \& Society, vol. 37, no 3, pp. 452-459.

y YEUNG, Wai Chung H. (2006), “Whither Global Production Networks? Past, Present and Future". Environment and Planning A, vol. 38, no 7, pp. 1193-1204.

HOPKINS, Terence y WALLERSTEIN, Immanuel. (1977), "Patterns of Development of the Modern World-System". Review, vol. 1, no 2, pp. 111-145.

(1986), "Commodity Chains in the World Economy Prior to 1800". Review, vol. 10, no 1, pp. 157-170. 
HUMPHREY, John y SCHMITZ, Hubert. (2002), "How Does Insertion in Global Value Chains Affect Upgrading in Industrial Clusters?". Regional Studies, vol. 36, no 9, pp. 1017-1027.

JESSOP, Bob. (1999), "Narrating the Future of the National Economy and the National State? Remarks on Remapping Regulation and Reinventing Governance", in G. Steinmetz (ed.), State/Culture: State Formation after the Cultural Turn. Ithaca, Cornell University Press, pp. 378-405.

KOHLI, Atul. (2004), State-Directed Development. Political Power and Industrialization in the Global Periphery. Cambridge, UK, Cambridge University Press.

KOJIMA, Kiyoshi. (2000), “The 'Flying Geese' Model of Asian Economic Development: Origin, Theoretical Extensions, and Regional Policy Implications". Journal of Asian Economics, vol. 11, pp. 375-401.

LATOUR, Bruno. (2005), Reassembling the Social: An Introduction to Actor-Network-Theory. Oxford, Oxford University Press.

LEE, Kwangkun. (2009), “Towards a Reformulation of Core/Periphery Relationship: A Critical Reappraisal of the Trimodality of the Capitalist World-Economy in the Early 21st Century". Perspectives on Global Development and Technology, vol. 8, no 2, pp. 263-294.

LINDEN, Greg; KRAEMER, Kenneth y DEDRICK, Jason. (2009), “Who Captures Value in a Global Innovation Network?". Communications of the ACM, vol. 52, no 3, pp. 140-144.

LUND-THOMSEN, Peter y NADVI, Khalid. (2010), “Global Value Chains, Local Collective Action and Corporate Social Responsibility: A Review of Empirical Evidence". Business Strategy and the Environment, vol. 19, no 1, pp. 1-13.

MADDISON, Angus. (2006), The World Economy: A Millennial Perspective. Paris, Development Centre Studies, OECD Publishing.

MESSNER, Dirk. (2002), "The Concept of the 'World Economic Triangle', Global Governance Patterns and Options for Regions". IDS Working Paper, vol. 173.

MOHANTY, Chandra T. (2002), “Under Western Eyes Revisited: Feminist Solidarity through Anticapitalist Struggles". Journal of Women in Culture and Society, vol. 28, no 2, pp. 499-535.

NAVARRO, Vicente. (1982), "The Limits of the World Systems Theory in Defining Capitalist and Socialist Formations". Science \& Society, vol. 46, no 1, pp. 77-90.

NIELSEN, Jeffrey. (2014), “Value Chains, Neoliberalism and Development Practice: The Indonesian Experience". Review of International Political Economy, vol. 21, no 1, pp. 38-69.

PECK, Jamie y TICKELL, Adam. (1994), "Searching for a New Institutional Fix: The After-Fordist Crisis and the Global-Local Disorder", in A. Amin (ed.), Post-Fordism. A Reader. Oxford, Blackwell, pp. 280-315.

PIETROBELLI, Carlo y STARITZ, Cornelia. (2013), “Challenges for Global Value Chain Interventions in Latin America". Technical Note 548, Inter-American Development Bank, Competitiveness and Innovation Division. 


\section{Víctor Ramiro Fernández y Manuel Facundo Trevignani}

ROBINSON, William. (2011), "Globalization and the Sociology of Immanuel Wallerstein: A Critical Appraisal”. International Sociology, vol. 26, no 6, pp. 723-745.

RODRIK, Dani. (2011), The Globalization Paradox, Democracy and the Future of the World Economy. New York, W.W. Norton \& Company.

SCHMITZ, Hubert y KNORRINGA, Peter. (2000), "Learning from Global Buyers". Journal of Development Studies, vol. 37, no 2, pp. 177-205.

SHEPPARD, Eric y NAGAR, Richa. (2004), "From East-West to North-South". Antipode, vol. 36, no 4, pp. 557-563.

SMITH, Adrian et al. (2002), "Networks of Value, Commodities and Regions: Reworking Divisions of Labour in Macro-Regional Economies". Progress in Human Geography, vol. 26, no 1, pp. 41-63.

SKOCPOL, Theda. (1977), "Wallerstein's World Capitalist System: A Theoretical and Historical Critique". American Journal of Sociology, vol. 82, no 5, pp. 1075-1090.

STURGEON, Timothy. (2008), "From Global Commodity Chains to Global Value Chains: Interdisciplinary Theory Building in an Age of Globalization", in J. Bair (ed.), Frontiers of Commodity Chain Research. Stanford, Stanford University Press, pp. 110-135.

WADE, Robert. (1990), Governing the Market. Economic Theory and the Role Government in East Asian Industrialization. Princeton, Princeton University Press.

WALLERSTEIN, Immanuel. (1974), “The Rise and Future Demise of the World Capitalist System: Concepts for Comparative Analysis". Comparative Studies in Society and History, vol. 16, no 2, pp. 387-415.

(1976), The Modern World System I: Capitalist Agriculture and the Origins of the European World-Economy in the Sixteenth Century. New York, Academic Press.

. (2004a), The Uncertainties of Knowledge. Philadelphia, Temple University Press.

. (2004b), World-Systems Analysis: An Introduction. Durham, Duke University Press.

WEISS, Linda. (2003), "Introduction: Bringing Domestic Institutions Back In", in L. Weiss (ed.), States in the Global Economy. Bringing Domestic Institutions Back In. Cambridge, Cambridge University Press, pp. 1-35.

WERNER, Marion; BAIR, Jennifer y FERNÁNDEZ, Víctor R. (2014), “Linking Up to Development? Global Value Chains and the Making of a Post-Washington Consensus". Development and Change, vol. 45, no 6, pp. 1219-1247.

\section{Bases de datos consultadas:}

Banco Mundial, www.bancomundial.org, (fecha de acceso: Octubre 2013).

Fortune, money.cnn.com/magazines/fortune (fecha de acceso: Octubre 2013).

United Nation Conference on Trade and Development (UNCTAD), www.unctadstat.unctad.org, (fecha de acceso: Octubre 2013). 


\section{RESUMO \\ Cadeias Globais de Valor e Desenvolvimento: Perspectivas Críticas do Sul Global}

Este artigo realiza una interpretação teórica crítica das cadeias globais de valor, entendidas como uma relevante ferramenta para a análise dos processos de globalização, tanto na academia como no nível institucional, a partir da formulação de estratégias de desenvolvimento promovidas por governos e organismos internacionais no Sul Global. Após discutir a evolução do conceito em perspectiva comparada com a teoria do sistema-mundo, destacam-se suas fragilidades fundadas tanto em aspectos vinculados ao distanciamento de dita teoria como nas limitações surgidas da base teórica compartilhada por ambos. As restrições para compreender a inalterada recriação da estrutura hierárquica e desigual do capitalismo e a heterogeneidade e divergência de cenários no Sul Global emergem como as principais limitações teórico-empíricas. Deste modo, o trabalho conclui apontando alguns desafios orientados a superá-las.

Palavras-chave: cadeias globais de valor; desenvolvimento; Sul Global; teoria do sistema-mundo

\section{ABSTRACT \\ Global Value Chains and Development: Critical Perspectives from the Global South}

This article carries out a theoretical critique of the global value chains, understood as a relevant tool in the analysis of the processes of globalization, not only at the academic level but at the institutional level as well, based on the formulation of development strategies promoted by governments and international organizations in the Global South. Taking into account the evolution of the concept from a compared perspective in relation to the world-system theory from which it stemmed, the shortcomings based either on a distancing from said theory or as a result of the limitations that are a product of the theoretical platform they share. The restrictions to understand the reproduction of the hierarchical and unequal structure of capitalism and the diverging scenarios within the Global South emerge as the main theoretical-empirical obstacles. In this sense, the article concludes underlining some challenges that must be overcome.

Keywords: global value chains; development; Global South; world-system theory

DADOS - Revista de Ciências Sociais, Rio de Janeiro, vol. 58, nº 2, 2015 


\author{
RÉSUMÉ \\ Chaînes Globales de Valeur et Développement: Perspective Critiques \\ depuis le Sud Global
}

Cet article propose une interprétation théorique et critique des chaînes globales de valeur, entendues ici comme un outil pertinent pour l'analyse des processus de mondialisation, au niveau académique comme à l'échelle institutionnelle, à partir de la formulation des stratégies de développement mises en œuvre par les gouvernements et les organismes internationaux dans le Sud global. En nous basant sur les évolutions du concept et ses rapports avec la théorie du système-monde qui lui a donné naissance, nous en soulignerons les fragilités, fondées aussi bien sur des aspects liés à l'éloignement de ladite théorie que sur les limitations issues de la plate-forme théorique qu'ils partagent. Les restrictions à la compréhension de la reproduction constante de la structure hiérarchique et inégalitaire du capitalisme, ainsi que les scénarios divergents qui se dessinent au sein du Sud global, s'imposent comme les limitations théorico-empiriques les plus pertinentes. Nous conclurons ainsi ce travail en soulignant quelques-uns des défis à relever pour les dépasser.

Mots-clés: chaînes globales de valeur; développement, Sud global; théorie du système-monde

\title{
RESUMEN
}

Cadenas Globales de Valor y Desarrollo: Perspectivas Críticas desde el Sur Global

Este artículo realiza una interpretación teórica crítica de las cadenas globales de valor, entendidas como una relevante herramienta para el análisis de los procesos de globalización, no sólo a nivel académico sino a nivel institucional, a partir de la formulación de estrategias de desarrollo promovidas por gobiernos y organismos internacionales en el Sur Global. Teniendo en cuenta la evolución del concepto a partir de una perspectiva comparada con la teoría del sistema-mundo que le diera origen, se destacan las debilidades fundadas tanto en aspectos ligados al distanciamiento respecto de dicha teoría, como en los limitantes que surgen producto de la plataforma teórica que ambas comparten. Las restricciones para comprender la inalterada recreación de la estructura jerárquica y desigualadora del capitalismo, y los divergentes escenarios al interior del Sur Global, emergen como los limitantes teórico-empíricos más importantes. En este sentido, el trabajo concluye subrayando algunos desafíos orientados a superarlos.

Palabras clave: cadenas globales de valor; desarrollo; Sur Global; teoría de sistema-mundo 